\title{
Application of Pinch Analysis in an Integrated Steel Plant in Northern Sweden
}

\author{
Carl-Erik GRIP, ${ }^{1) *}$ Johan ISAKSSON, ${ }^{2)}$ Simon HARVEY ${ }^{2)}$ and Leif NILSSON ${ }^{3)}$ \\ 1) Div. of Energy Engineering, Luleå University of Technology, Luleå, Sweden. \\ Chalmers University of Technology, Göteborg, Sweden. \\ 3) SSAB EMEA, Luleå, Sweden.
}

(Received on October 22, 2012; accepted on March 26, 2013)

\begin{abstract}
The energy system in a modern integrated steel plant is a complicated network of units exchanging energy and matter with each other. System studies using process integration tools are important to avoid sub-optimization. At the steel plant in Luleå such studies have been carried out using a MILP-based mathematical programming tool (reMIND), mainly because of its inherent flexibility for handling combined flows and reactions of both matter and chemical, thermal and mechanical energy. There are, however, areas where the energy system is dominated by creation, transport and exchange of thermal energy, and where pinch analysis can be expected to be a valuable tool. For this reason a pinch targeting study was carried out for the plant site of the integrated steel plant in Luleå. The coke plant and the iron making/ steelmaking plant were both studied with three ambition levels of possible improvements. The study confirmed that pinch analysis is a powerful tool for targeting energy savings in areas where thermal energy flows dominate the local energy system, e.g., the gas cleaning area at the coke plant. The study also indicated that a connection between the energy systems in the coke plant and the iron making/steelmaking would be valuable. This is not $100 \%$ feasible because of distance, but, a common steam net could add a degree of flexibility.
\end{abstract}

KEY WORDS: pinch analysis; energy efficiency; integrated steel plant; process integration; system optimization; rest energy.

\section{Introduction}

\subsection{Short Description of Plant Site}

The energy system studied in this work consists of the integrated steel plant in Luleå, the local Combined Heat and Power (CHP) plant and the district heating system in Luleå. The main units of the steel plant are a Coke plant, a Blast Furnace, two Basic Oxygen Furnaces (BOF) converters, Ladle metallurgy and two Slab casters. The coal is converted to coke by dry distillation in the coke plant. Approximately $25 \%$ of the weight is recovered as energy rich raw gas; the rest is coke. The raw gas is sent to the gas cleaning plant where it is cleaned from excess water, tar, dust, naphthalene, sulphur, ammonia and benzene. These cleaning units consume a lot of heat in the form of steam. The steam is not available at the coke plant. Instead, it is generated in a local steam boiler which produces steam at 14.6 bar, (gauge pressure) using coke oven gas as fuel. The steam at 14.6 bar is throttled down to 13.6 bar (HP steam), 9 bar (MP steam) and 2.7 bar (LP steam). As most steam is used for direct heating, very little of the condensate is fed back to the boiler. Generation of this steam constitutes a substantial fraction of the heat balance of the coke plant.

The Blast furnace works with a burden of $100 \%$ pellets

* Corresponding author: E-mail: carl-erik.grip@ltu.se

DOI: http://dx.doi.org/10.2355/isijinternational.53.1202 and produces hot metal with around $4.7 \%$ carbon and BF gas as a by-product. The hot metal is converted into steel in two BOF converters with BOF gas as a by-product. After ladle treatment the steel is cast into steel slabs in two slab casters. The cast slabs are transported approximately $800 \mathrm{~km}$ to the company's site in Borlänge where they are rolled into strip material. Normally, integrated steel mills use residual gases from the steel plant as fuel for reheating in the rolling mill. In this case that is not possible because of the distance. Instead the reheating furnace is heated with 7-8 PJ external fuel per year. In the steel plant this results in a surplus of process gases which is fired in a local CHP plant. This plant produces electricity covering the needs of the steel plant as well as district heating covering the needs of the community. In addition to these flows there are three steam systems in the blast furnace steel plant area; HP (15 bar gauge pressure), MP (8 bar) and a small LP net ( 6 bar). Dependent on the pressure level in the steam drums, the steam that is generated in the BOF-converters is transferred to either the HP or the MP system. HP steam is also delivered from the CHP plant to cover unbalances in steam balance.

The total energy input to the plant site is mainly coal (94\%). 36\% of the energy is exported as chemical energy in the steel and $35 \%$ as fuel gases and by products (tar, benzene, naphthalene, sulphur and coke fines). The remaining $29 \%$ or around $12 \mathrm{PJ}$ are rest energies that are not used at 
present. Figure 1 shows the approximate distribution of these residual energy flows. A major part is low value energy that is difficult to recover, e.g. cooling water at a few degrees above ambient, vented steam from the continuous caster and coke cooling, flue gases around $200-250^{\circ} \mathrm{C}$, cooling of slag and bay iron, heat released from hot surfaces etc.

One problem is that some processes, such as the blast furnace, are continuous while many processes in the steel plant are batch-wise. The impact on the steel plant steam balance is important for this study. The two converters operate independently of each other with a heat cycle of around $45 \mathrm{~min}$. BOF gas and high pressure steam are produced for around 15 minutes during each of these cycles. The steam goes directly to a steam dome (one per converter with a pressure range of 7.7-28 bar). The steam then goes to two steam accumulators (pressure range $7.7-18$ bar) which are connected and common for both converters. The domes and accumulators work together as a buffer which delivers steam to the consumers in the steam net. A large intermittent consumer is the RH vacuum furnace, which consumes steam in the range of 11.4 bar, during a sequence of heats, which is not synchronized with the BOF production. Extra steam high pressure is purchased from the CHP if there is not enough in the buffer. Some low pressure steam is also delivered to different heat consumers. There is a limited possibility to compensate fluctuations by a temporary decrease in that delivery. In case of excess the new steam from the BOF has to be cooled and condensed in order to prevent pressures above the 28 Bar level.

\subsection{Process Integration and Pinch Analysis}

Like most process industries, the plant site in Luleå does not consist of independent process units. Instead, it is a network of units exchanging energy and energy carriers with each other. The local community is also involved in the network through power generation and district heating. The different units exchange energy and material with each other. Changes in one unit affect the other units. Energy saving in one unit does not necessarily lead to energy saving of the total system. A global approach, "Process Integration", is needed to avoid sub-optimization. During the 1970s, researchers at the University of Manchester Institute of Science and Technology developed the pinch analysis method for more systematic studies of this type of problem. ${ }^{1)}$ The heat-carrying media are categorized as either cold streams (media that require heating during the process) or hot

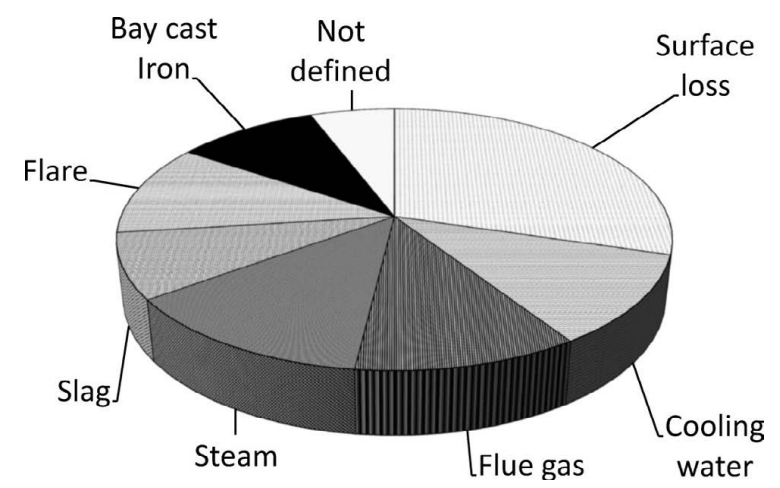

streams (media that require cooling), and information about heat loads and temperature levels are thereafter used to construct "composite curves", which can be used to analyze energy flows within the system. The method allows the user to establish energy targets for minimum usage of heating and cooling utilities. It also provides guidelines for heat exchanger network design in order to achieve the target. Pinch analysis is widely adopted as a tool to analyze and optimize energy systems dominated by transfer and exchange of thermal energy (see e.g. Refs. 2) 3) and 4). Other methods for analyzing energy efficiency measures in industry have been developed, for example Exergy analysis (e.g. Refs. 5) 6) and 7) and mathematical programming (e.g. Refs. 9) and 10). When process integration work was initiated for the steel plant site it had to be considered that the main input energy flow is coal and that the resulting processes are characterized by large high temperature flows of molten, solid and gaseous materials, as well as by energy intensive chemical reactions. Mathematical programming was considered suitable for optimizing energy flows in this type of system. An existing tool (MIND, see ${ }^{9)}$ was further developed into a tool (reMIND) especially suited for energy system studies of steelmaking plants. It was extensively used in different applications, see e.g. Refs. 11)-15). Relatively little work is reported on the use of pinch analysis in steel plants, despite the extensive number of reports on process integration in this sector. An unpublished study was performed at the Oxelösund plant in 1991. ${ }^{16)}$ A minor study with pinch analysis was made at the coke plant in Lulea.. ${ }^{17}$ Matsuda $^{18)}$ adopted a total site approach including usage of "Site Source Sink Profiles" (SSSP) to study a large steelmaking site.

The reMIND studies at the Luleå plant site were mainly focused on the high-value part of the energy system. However, in addition to the metallurgical system, there is also a parallel system that includes low value energy flows e.g. the residual energy flows shown in Fig. 1 and the heating and steam requirements of the coke plant and the steel plant. Exergy analysis was tried in order to categorize the residual energy flows. Exergy analysis was not, however, able to provide useful input regarding possible matching of the available residual energy flows with the need for steam and heat in other parts of the plant. Pinch analysis is usually considered to be a useful tool for this type of problem. A study to investigate the possible use of pinch analysis in the steel and mining sector was funded by the process integration research program of the Swedish Energy Agency during 2009-2010. A major part of that work was a pinch targeting study of the Luleå Steel plant system.

It has to be noted that the steel plant in Lulea has three main production units: the coke plant, the iron making plant with blast furnace and the steel making plant. There is a certain distance between the units, esp. between coke making and the rest of the plant. In principle, there are two subsystems which are only partly connected: the coke plant system and the Iron making/Steelmaking system. The targeting study was carried out as independent studies of these two systems followed by a discussion of the possible benefits that could be achieved if they could be connected.

Fig. 1. Distribution of residual energies. 


\subsection{Scope of Paper}

The main scope of this paper is to describe the above mentioned targeting study and the conclusions on possible use of pinch analysis in the steel industry.

\section{Methodology}

The methodology is described with the gas cleaning plant as an example. The same methodology was used to analyze the other subsystems and the total plant.

\subsection{Data Collection and Pinch Diagrams for Coke Plant Gas Cleaning}

Stream data were collected together with coke plant staff and characterized as cold streams, which are heated up in the process, and hot streams, which release heat. The principle of pinch analysis is to lump individual process streams together and regard them as two flows with common energy content, one composite cold stream and one composite hot stream. The procedure is well described, e.g. in Refs. 2) 3) and 4) is not discussed here. However, the pinch analysis guide of Canmet ${ }^{4)}$ can be looked upon as an introductory to the area. The cold and hot stream data (based on data collected for existing process heaters or heat exchangers) are shown in Tables $\mathbf{1}$ and 2. In Fig. 2 the lumped data is shown as hot and cold composite curves (CC) for the gas cleaning section of the coke plant. The vertical axis shows the tem-

Table 1. Heating loads of cold streams in the coke oven gas cleaning area.

\begin{tabular}{ccccc}
\hline Process part & $\mathrm{T}_{\text {start }}\left({ }^{\circ} \mathrm{C}\right)$ & $\mathrm{T}_{\text {end }}\left({ }^{\circ} \mathrm{C}\right)$ & Flow & Load $(\mathrm{kW})$ \\
\hline Ammonia stripper & MP steam & & & 5852 \\
-“- & 6.8 & 63 & $22 \mathrm{t} / \mathrm{h}$ & $\approx 1500$ \\
Benzene stripper & LP steam & & & 42.3 \\
- “- & LP steam & & & 633 \\
-“- & 178 & 178.1 & & 950 \\
- “- & 27 & 143 & $51.8 \mathrm{~m}^{3} / \mathrm{h}$ & 2620 \\
$2^{\text {nd }}$ feed water preheat & 63 & 124 & $22 \mathrm{t} / \mathrm{h}$ & 1566 \\
Sulfur stripper & 26 & 51 & $61.1 \mathrm{~m}^{3} / \mathrm{h}$ & 1770 \\
\hline
\end{tabular}

Table 2. Cooling loads of hot streams in the coke oven gas cleaning area.

\begin{tabular}{ccccc}
\hline Process part & $\mathrm{T}_{\text {start }}\left({ }^{\circ} \mathrm{C}\right)$ & $\mathrm{T}_{\text {end }}\left({ }^{\circ} \mathrm{C}\right)$ & Flow & Load $(\mathrm{kW})$ \\
\hline Gas cooler & 44 & 25 & $510 \mathrm{~m}^{3} / \mathrm{h}$ & 11228 \\
Naphthalene washer & 22 & 18 & $32 \mathrm{~m}^{3} / \mathrm{h}$ & 148 \\
Ammonia stripper & 52 & 29 & $18 \mathrm{~m}^{3} / \mathrm{h}$ & 480 \\
& 52 & 29 & $18 \mathrm{~m}^{3} / \mathrm{h}$ & 480 \\
& 84 & 52 & $36 \mathrm{~m}^{3} / \mathrm{h}$ & $\approx 1335$ \\
Sulfur stripper & 84 & 42 & $27 \mathrm{~m}^{3} / \mathrm{h}$ & 1336 \\
& 42 & 31 & $27 \mathrm{~m}^{3} / \mathrm{h}$ & 350 \\
Benzene washer & 103 & 18 & $43 \mathrm{~m}^{3} / \mathrm{h}$ & 2940 \\
& 53 & 25 & $32 \mathrm{~m}^{3} / \mathrm{h}$ & 3708 \\
& 181 & 53 & $32 \mathrm{~m}^{3} / \mathrm{h}$ & 2620 \\
\hline
\end{tabular}

perature, and the horizontal axis represents the change in enthalpy load over the temperature intervals. The curves can be moved horizontally as the values on the x-axis show an enthalpy change, not an absolute value. The hot stream curve is usually placed with the lowest value at $\mathrm{x}=0$. The cold stream curve is shifted horizontally so as to achieve maximum overlap (corresponding to maximum internal heat recovery within the process), limited by the minimum allowable temperature difference $\left(\Delta \mathrm{T}_{\min }\right)$ for heat exchange between hot and cold streams. The location at which this occurs is the pinch point. The curves were constructed using the stream data from and the computer software Pro pi. (Pro pi is an Excel add-in developed for pinch analysis studies by Per-Åke Franck, former PhD student at the Division of Heat and Power Technology at Chalmers). $\Delta \mathrm{T}_{\min }$ was set at $10 \mathrm{~K}$ in this study. Internal heat recovery is theoretically possible where the curves overlap (shaded area). A larger $\Delta \mathrm{T}_{\min }$ would push the curves further apart, thus decreasing the overlap and cause an increasing demand for heating and cooling media $\left(\mathrm{Q}_{\mathrm{H} \text {,minimum }}\right.$ and $\left.\mathrm{Q}_{\mathrm{C}, \text { minimum }}\right)$. (On the other hand a higher driving force could facilitate an increased production rate as well as lower cost for heat exchanger area).

The region above the pinch is characterized by a heat deficit, while the region below the pinch is characterized by heat surplus. With this in mind three "golden rules" must be respected when designing heat exchanger networks that can achieve maximum heat recovery for a given value of the minimum driving force acceptable for heat exchanging $\left(\Delta \mathrm{T}_{\min }\right)$. Any violation of these rules will result in increased demand for external cooling or heating or both.

1. Do not add external heat to streams below pinch.

2. Do not add external cooling to streams above pinch.

3. Do not transfer heat down through the pinch.

In Fig. 3 the curves have been converted into a grand composite curve diagram (GCC) for the gas cleaning area. This was made by moving the hot and cold composite curves respectively $1 / 2 \Delta \mathrm{T}_{\min }$ downwards and upwards until they come into close contact and then plotting the horizontal difference vs. temperature. The figure illustrates constant temperature utility streams. Note that when multiple utility levels are available for the hot utility, the ones with temperatures closest to the pinch point are often the cheapest one.

The GCC curve can be used to determine whether there is any heat surplus (below the pinch) at useful levels, which

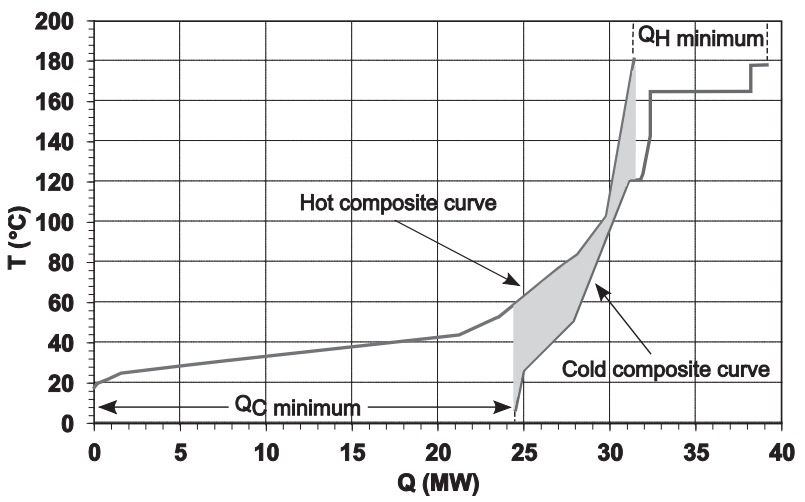

Fig. 2. Composite curves (CC) for the coke plant's gas cleaning area 


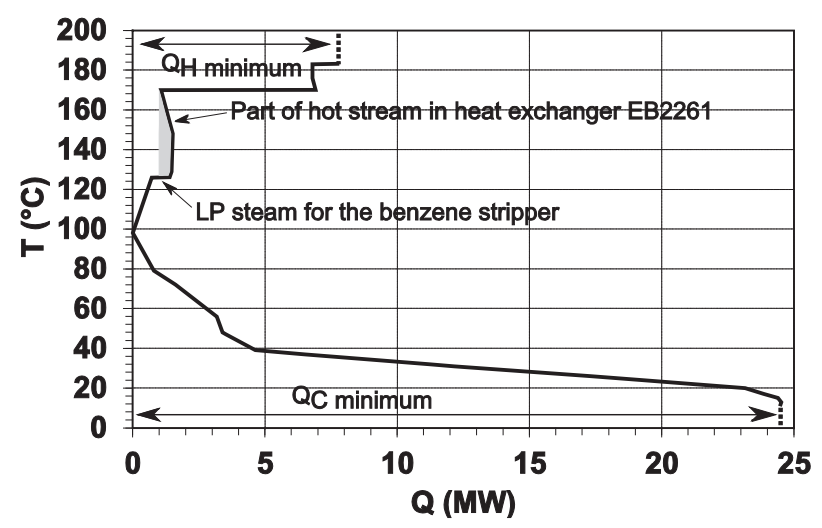

Fig. 3. Grand composite curve for the coke plant's gas cleaning area.

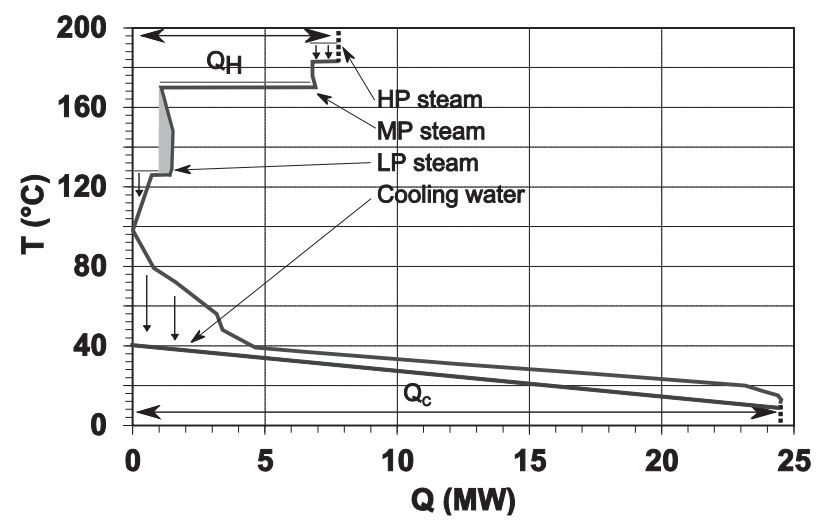

Fig. 4. Balanced GCC with current steam levels in red, placed to use as low steam pressure as possible, and the cooling water stream in blue, going from around 10 to $40^{\circ} \mathrm{C}$.

could be used for steam generation, district heating, electricity production in a Rankine cycle, etc. The shaded part shows where internal heat exchange between temperature intervals is possible, i.e. a so-called pocket. The curve shows that part of the hot stream in the Benzene washer can be used to generate LP steam for the benzene stripper.

A stepwise study was carried out to study the possibility to improve heat recovery by process changes. The first step studied the consequences of using steam at as low pressure as possible. This is particularly important when the steam is extracted from a turbine, in order to maximize electricity production. Figure 4 shows an example of the heating and cooling loads in the coke plant area when steam available at three pressure levels and cooling water are included. The heat flows according to the vertical arrows; from the condensing steam to the process and from the process to the cooling water.

Step 2 studied the effect of increased recovery of excess heat from cooling of the raw gas and from the flue gas. One problem is that steam is directly mixed with the process streams in some places. Such direct heating cannot be replaced by heat recovery from process streams, without changing process conditions. Instead, an intermediate step must be introduced where; in this case, flue gases generate steam, which in turn can be used wherever desired. In practice, a flue gas heat recovery boiler would have to be installed. In order to make a realistic estimate of the amount of steam that could be generated in this way, the $\Delta \mathrm{T}_{\text {min }}$ for the flue gas stream was doubled to $20^{\circ} \mathrm{C}$. In this way the flue gases can generate steam, which in turn can heat the strippers, and still maintain a $\Delta \mathrm{T}_{\min }$ of $10^{\circ} \mathrm{C}$. Heat must therefore also be supplied to heat up the boiler feed water from river temperature $\left(6.8^{\circ} \mathrm{C}\right)$ to the boiling point, in this case $1.2 \mathrm{MW}$. Otherwise the methodology is the same as for Step 1.

Step 3 studied the effect of recovering high temperature heat from the raw gas. The evaluation methodology was similar to the one used for step 1. The details and outcome are discussed in the Results section.

\subsection{Coking Battery}

The heat for the coking is created by a coke oven gas burner with air preheating through a regenerative heat exchanger. These units are positioned underneath the battery where air is taken in and flue gases are discharged. The flue gases are currently used to preheat the incoming combustion air, so consequently their respective heat loads cancel out. As the regenerative shaft, where air and flue gases exchange heat, is embedded in the construction of the coke plant, separate from other streams, it is unlikely that alternative usage of this heat would make economic sense. For that reason, this part was not included in this initial step of the pinch analysis study.

\subsection{Blast Furnace and Steel Plant}

The blast furnace and the steel plant (including desulfurization, BOF-converters, CAS-OB, RH and continuous casting) were treated as a single process area in this pinch analysis due to the relatively short distance between the two areas. Data for the hot and cold streams were collected using the same methodology as for the coking plant. The stream data are shown in Tables 3 and 4. One problem is fluctuations to batch production, for example the steam from the BOF converters. The logged value is measured as an instantaneous value of the intermittent flow leaving the waste gas boilers, which is measured before entering the buffer system (steam domes + steam accumulators). The physical value that is relevant to the study is instead the amount of steam entering the net from these accumulators. In this study it was approximated as a continuous flow corresponding to the mean value of the instantaneous flow. Table 4 shows the instantaneous flow rate with the calculated mean flow in brackets. The possible consequences of this approximation are discussed in paragraph 4.1.

Also for this case a three step study of possible improvements was carried out.

- Step 1 investigated the possibility to use BOF steam for preheating in the hot stove area

- Step 2 investigated the opportunity to recover heat from flue gases

- Step 3 examined the effect of possible process modifications that could improve heat recovery from BOF gas and optimized water cooling

The methodology was identical to the one used for the coke plant study. Details and outcome are presented in the Results section. 
Table 3. Heating loads of cold streams in the iron making and steelmaking area.

\begin{tabular}{llrccr}
\hline Unit & \multicolumn{1}{c}{ Cold stream } & $\mathrm{T}_{\text {start }},{ }^{\circ} \mathrm{C}$ & $\mathrm{T}_{\text {end }},{ }^{\circ} \mathrm{C}$ & Flow & Load, $\mathrm{kW}$ \\
\hline BF & Blast air & 155 & 1108 & $61.5 \mathrm{Nm}^{3} / \mathrm{s}$ & 76778 \\
BOF & Steam generation & $198(\mathrm{l})$ & $198(\mathrm{~g})$ & $11 \mathrm{tons} / \mathrm{h}$ & 5950 \\
RH & Steam demand & $198(\mathrm{l})$ & $198(\mathrm{~g})$ & & 426 \\
$\mathrm{C} / \mathrm{C}$ & Mould cooling water & 42 & 35 & 834 & 6823 \\
$\mathrm{C} / \mathrm{C}$ & Strand guide cooling water & 32 & 26 & 1429 & 10017 \\
$\mathrm{C} / \mathrm{C}$ & Engine cooling water & 39 & 35 & 823 & 3847 \\
\hline
\end{tabular}

Table 4. Cooling loads of hot streams in the iron making and steelmaking area.

\begin{tabular}{|c|c|c|c|c|c|}
\hline Unit & Hot streams & $\begin{array}{l}\mathrm{T}_{\text {start }} \\
\left({ }^{\circ} \mathrm{C}\right)\end{array}$ & $\mathrm{T}_{\text {end }}\left({ }^{\circ} \mathrm{C}\right)$ & Flow & Load (kW) \\
\hline $\mathrm{BF}$ & $\begin{array}{l}\text { Cooling water, } \\
\text { blower }\end{array}$ & 10 & 4 & $40 \mathrm{~m}^{3} / \mathrm{h}$ & 278 \\
\hline $\mathrm{BF}$ & $\begin{array}{l}\text { Cooling water, } \\
\text { hot stoves }\end{array}$ & 8 & 4 & $557 \mathrm{~m}^{3} / \mathrm{h}$ & 2582 \\
\hline $\mathrm{BF}$ & Staves/furnace base & 25.7 & 21 & $3121 \mathrm{~m}^{3} / \mathrm{h}$ & 17005 \\
\hline $\mathrm{BF}$ & Blast air nozzles & 17 & 13 & $562 \mathrm{~m}^{3} / \mathrm{h}$ & 2606 \\
\hline $\mathrm{BF}$ & Other nozzles & 19 & 17 & $2524 \mathrm{~m}^{3} / \mathrm{h}$ & 5851 \\
\hline $\mathrm{BOF}$ & BOF gas & 1600 & 1225 & $47444 \mathrm{Nm}^{3} / \mathrm{h}$ & 8890 (5 927) \\
\hline $\mathrm{BOF}$ & $\begin{array}{l}\text { Closed loop } \\
\text { cooling water }\end{array}$ & 27 & 22 & $350 \mathrm{~m}^{3} / \mathrm{h}$ & $2027(1352)$ \\
\hline $\mathrm{BOF}$ & $\begin{array}{l}\text { Oxygen lance } \\
\text { cooling }\end{array}$ & 16.8 & 6.8 & $180 \mathrm{~m}^{3} / \mathrm{h}$ & $2085(1390)$ \\
\hline BOF & Washing water & 69 & 50 & $270 \mathrm{~m}^{3} / \mathrm{h}$ & 5945 (3963) \\
\hline
\end{tabular}

\section{Results}

\subsection{Coke Plant Gas Cleaning}

The pinch diagrams are shown in Figs. 2 and 3. Based on these data three possible steps to improve the heat balance were studied, as described above. The main results are shown in Table 5.

The difference between Step 1 ("Optimized steam" in the table) and current operations indicates that the steam demand in the process can theoretically be reduced by $1290 \mathrm{~kW}$ (14\%), by adopting relatively simple changes. There are three reasons for this steam saving potential:

- The current usage of LP steam to heat up the feed water in the feed water tank is the main reason for the "waste" of hot utility in the process. Steam at a temperature above the pinch is used to heat a stream which is partly located below the pinch (heated from 63 to $124^{\circ} \mathrm{C}$ with the cold pinch at $93^{\circ} \mathrm{C}$ ), i.e. a pinch violation. The cooling demand will therefore increase just as much as heat is supplied below the pinch where there is already an excess of heat. The feed water tank violation accounts for $770 \mathrm{~kW}$.

- $60 \mathrm{~kW}$ of LP steam can be saved above the pinch due to reduced need for feedwater preheating.

- The remaining $470 \mathrm{~kW}$ of possible heat savings is due to transfer of heat through the pinch in an existing heat exchanger, which has to be covered by external utility.

The current cooling requirement is $24.5 \mathrm{MW}$, of which part could potentially be reused; either directly for example by preheating a district heating stream, by heat pumping for
Table 5. Coke oven gas cleaning. Calculated effect $(\mathrm{kW})$ of three step improvement.

\begin{tabular}{ccccc}
\hline Hot utility & Current load & $\begin{array}{c}\text { Optimized } \\
\text { steam }\end{array}$ & $\begin{array}{c}\text { Extended } \\
\text { Heat recovery }\end{array}$ & $\begin{array}{c}\text { Modified raw } \\
\text { gas cooling }\end{array}$ \\
\hline HP & 950 & 950 & 0 & 0 \\
MP & 5852 & 5727 & 3540 & 0 \\
LP & 2233 & 1068 & 0 & 0 \\
\hline Sum & 9035 & 7745 & 3540 & 0 \\
Cold utility & Current load & $\begin{array}{c}\text { Optimized } \\
\text { steam }\end{array}$ & $\begin{array}{c}\text { Extended } \\
\text { Heat recovery }\end{array}$ & $\begin{array}{c}\text { Modified raw } \\
\text { gas cooling }\end{array}$ \\
\hline HP level & 0 & 0 & 0 & 462 \\
LP generation & 0 & 0 & 300 & 0 \\
Cooling water & 25676 & 24502 & 25425 & 24598 \\
\hline
\end{tabular}

additional district heating supply or for electricity production in an Organic Rankine cycle. The temperature levels at which this heat is available are, however, very moderate (in the range of $40^{\circ} \mathrm{C}$ ), and probably not economically interesting at the present technological level.

The modifications proposed in Step 2 ("Extended heat recovery" in table) result in a minimum heating requirement that is $61 \%$ lower than the current practice, while the same amount of cooling water is needed. A few unutilized sources of excess heat were identified within the coke plant, as discussed below:

- The raw coke oven gas has a temperature of around $700-800^{\circ} \mathrm{C}$ when leaving the ovens. To minimize the risk of explosion and to remove some of the tar, the gas is instantly quenched to $80^{\circ} \mathrm{C}$ by direct injection of water. It would of course be desirable to utilize this heat at the highest possible temperature. Approximately 3.15 tons of tar are washed out every hour using around $1400 \mathrm{~m}^{3}$ of water at approximately $74^{\circ} \mathrm{C}$. The heat content of the cooled gas flow causes a $5 \mathrm{~K}$ temperature increase of the washing water which equals 8.1 MW of energy. The cooling water circulates in a closed system where tar is continuously removed. Due to the water content of the coal, a surplus of water is created in the system, which is lead off and sent to waste water treatment. It is not clear where all the heat goes since no cooling of the water appears to occur during the waste water treatment process. This load, defined by the $5 \mathrm{~K}$ temperature increase of the washing water mentioned above, is included in the GCC to show available heat, but will not contribute to the total cooling water demand, as such is not needed today. This water is hereafter referred to as washing water.

- The temperature of the flue gases from the under-firing is $272^{\circ} \mathrm{C}$ after the regenerative shaft and this stream could be further cooled to recover more heat, which can be used for process stream heating above the pinch temperature. According to internal studies the acid dew point for the flue gases is around $130^{\circ} \mathrm{C}$, thus some safety margin should be kept. $150^{\circ} \mathrm{C}$ was used in this study.

- Some excess heat is also available in the steam boiler flue gases. However, one should be aware that if demand for steam is decreased, the amount of flue gas- 
es from the steam boiler will decrease proportionally. This heat is thus difficult to quantify and it was not included in the analysis.

Excess heat is available at three temperature levels. About $300 \mathrm{~kW}$ is available at $150^{\circ} \mathrm{C}$ which could be used to generate LP steam. However, this amount is small and it was considered to be insignificant within the framework of a screening study.

Excess heat at lower temperatures is available at two distinct temperature levels: one at $75^{\circ} \mathrm{C}$ and one between 40 and $20^{\circ} \mathrm{C}$. This heat could be used for preheating district heating water, but since the distance between the coke plant and the CHP plant is $2.3 \mathrm{~km}$, it was not considered realistic to transport district heating water all the way just to preheat it a few degrees.

In Step 3 the introduction of a more extensive gas cooling improved heat recovery by around $9 \mathrm{MW}$ due to the following:

A lot of heat at high temperature is wasted when washing water at around $70^{\circ} \mathrm{C}$ is used to cool the hot coke oven gas directly after it leaves the ovens. It could be possible to heat exchange the gas down to the tar dew point, thus recovering the heat at high temperature, and then wash the gas, as currently is being done, in order to avoid problems with condensing tar in the heat exchanger. According to ${ }^{19)}$ different tars typically have dew points between 350 and $150^{\circ} \mathrm{C}$. A temperature of $450^{\circ} \mathrm{C}$ is used as inlet temperature in a described tar removal unit and will therefore be used as target temperature in this study. If the specific heat of the gas is assumed to be constant between 700 and $80^{\circ} \mathrm{C}$, it would mean that $40 \%$ of the energy is in the range from 700 to $450^{\circ} \mathrm{C}$. In a real implementation it would probably be necessary to have a hot oil circulating system between the off gases and the heat sink, in order to avoid fouling problems. $\Delta \mathrm{T}_{\text {min }}$ is therefore set at $20^{\circ} \mathrm{C}$ for the off-gas stream. In practice, the higher value of $\Delta \mathrm{T}_{\min }$ will not affect the overall heat loads, as the off gas stream is so much warmer than everything else.

It is assumed that the existing gas washing procedure will be used, in one way or another, in order not to affect the downstream process. The same water flow will be needed to extract the same amount of tar, thus the temperature increase of this water would be less $(-40 \%)$.

Based on previous figures $3.2 \mathrm{MW}$ is available down to $450^{\circ} \mathrm{C}$ and 4.9 MW will still be discharged with the washing water; now causing a three degree temperature lift, instead of five in the previous step. By introducing additional available heat at high temperature, the demand for external heat is now almost eliminated. The demand for cooling remains approximately the same. The system now displays a double pinch, with one pinch remaining at $98^{\circ} \mathrm{C}$ and a new one at $170^{\circ} \mathrm{C}$.

In order to include as much information as possible in this final analysis, the combustion air preheating was also accounted for. $\Delta \mathrm{T}_{\min }$ is kept at $80^{\circ} \mathrm{C}$ for this part, according to the current design. The inclusion of the air preheating/flue gas cooling eliminates the need for hot utility in the system and opens up for a possibility to utilize excess heat at high temperature $(\approx 0.5 \mathrm{MW})$.

In practice, the flue gas stream would have to be split; one part of it to be used for heating of combustion air, as is cur- rently done, and the other to be used for heating of other parts of the process. This is possible by using excess heat from the process at low temperature to start preheating the air at $35^{\circ} \mathrm{C}$, instead of using hot flue gases at $272^{\circ} \mathrm{C}$.

In this study, high temperature excess heat was assumed to be utilized to generate steam at HP level. However, since there is no internal steam demand at this pressure level, this option is of interest only if it can be supplied to external users.

In summary, the pinch analysis of the coke plant and the neighboring gas cleaning facility showed good potential for extended energy recovery. $9 \mathrm{MW}$ of external heat is currently used to run the plant, whereas in a best case scenario this external heating demand could be fully eliminated. However, the economy of such improvements was not investigated in the study.

The GCC diagram after the final step is shown in Fig. 4, left hand diagram.

\subsection{Blast Furnace and Steel Plant}

The stream data in Tables 3 and 4 was used to construct the GCC diagram for the current state (Fig. 4, right hand diagram). Basically, what the GCC suggests is that the steam generated by the BOF converters should be used to preheat the cold blast (the shaded pocket). This is not $100 \%$ feasible in practice. The practical interpretation of this is discussed in paragraph 4.2.

It is complicated to compare loads related to the $\mathrm{RH}$ vacuum degasser. The current load at $430 \mathrm{~kW}$ of HP steam should be treated as internal heat exchange, as the demand is covered by the steam from the BOF-converters. Using the available pinch curves, a study of possible improvements in three steps was carried out. The outcome is summarized in Table 6.

- Step 1 "Optimization" involved use of BOF steam for preheating in the BF blast area.

- Step 2 "Extended flue gas recovery": Flue gases of different kinds can potentially contribute additional excess heat within this area. Blast furnace gas and flue gases from the hot stoves could be of interest to study. Gases from the hot stoves currently have a fairly high outlet temperature and could be further utilized. Blast furnace gas has a lower outlet temperature but comes in large quantities. Particles are removed from the blast furnace gas in cyclones and a wet scrubber where the temperature drops to $30^{\circ} \mathrm{C}$. The target temperature for

Table 6. Blast furnace and steel plant. Calculated effect $(\mathrm{kW})$ of three step improvement.

\begin{tabular}{crccc}
\hline Hot utility & $\begin{array}{c}\text { Current } \\
\text { Load }\end{array}$ & Optimization & $\begin{array}{c}\text { Extended } \\
\text { flue gas } \\
\text { recovery }\end{array}$ & $\begin{array}{c}\text { Extended } \\
\text { BOF gas } \\
\text { Cooling }\end{array}$ \\
\hline Hot stoves & 76778 & 74111 & 69460 & 69460 \\
Cold utility & $\begin{array}{c}\text { Current } \\
\text { Load }\end{array}$ & Optimization & $\begin{array}{c}\text { Extended } \\
\text { flue gas } \\
\text { recovery }\end{array}$ & $\begin{array}{r}\text { Extended } \\
\text { BOF gas } \\
\text { Cooling }\end{array}$ \\
\hline HP/MP level & 5501 & 2834 & 5244 & 533 \\
Hot water & 0 & 0 & 8672 & 3300 \\
Cooling water & 51751 & 55738 & 55737 & 51774 \\
\hline
\end{tabular}




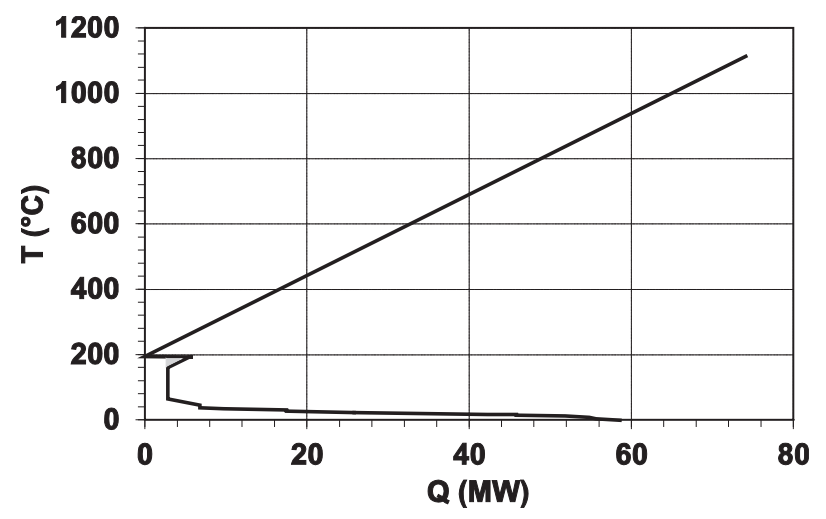

Fig. 5. Iron and steel making plant: GCC for existing demand.
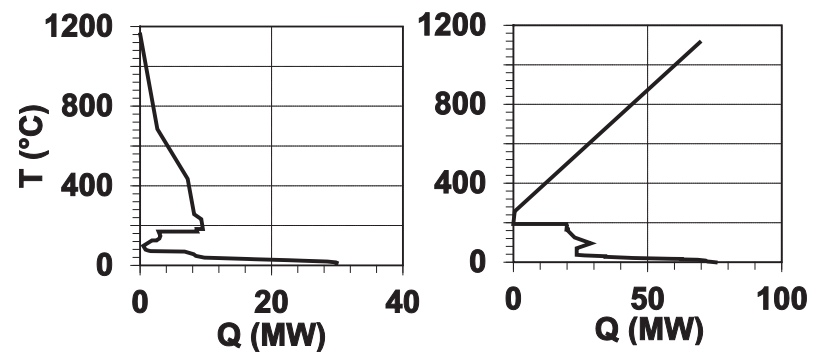

Fig. 6. GCC for the coke plant (left) and blast furnace and steel plant (right). Step 3 is used in both cases.

these gases was set at $100^{\circ} \mathrm{C}$ in the analysis in order to be able to investigate transfer of the heat to a useful energy carrier (hot water). Most of the heat from these gases is at levels below the pinch temperature in the GCC. Thus, the possibility to lower demand for external hot utility is quite restricted. Off-gases from ladle metallurgy have high temperatures, but have an intermittent behavior. Their contribution will therefore not be taken into account here. Some heat at high temperature (above the pinch at $193^{\circ} \mathrm{C}$ ) from the flue gases could be used to heat the blast air, which would decrease fuel consumption in the hot stoves. Further hot water and steam production would be possible. Available heat below the pinch increases by $21 \%$. Almost $14 \mathrm{MW}$ of the excess heat is at a useful level, compared to $5.5 \mathrm{MW}$ at the moment.

- Step 3 "Extended BOF gas Cooling". The GCC resulting from this step is shown in Fig. 6, right hand diagram. Note that not only is heat now available at higher temperature, the amount of energy has increased significantly. That is because around $10 \%$ of the washing water is currently evaporated in the filter tower and is discharged with the gas. Again, the BOF gas cannot be directly inserted in the GCC as it would appear as if it is a continuous source of energy. The additional latent heat in the BOF gases will instead be represented by 14.5 MW of HP steam and 0.5 MW of MP steam. The hot utility demand remains the same as in step 2 , since no additional heat is available above the pinch. The resulting utility levels from Fig. 6 are tabulated in Table 6. One should be aware that what appears to be a stable, continuous source of steam at HP level might not be as stable in reality. This is dependent on the operation of the converters and the fluctuations caused

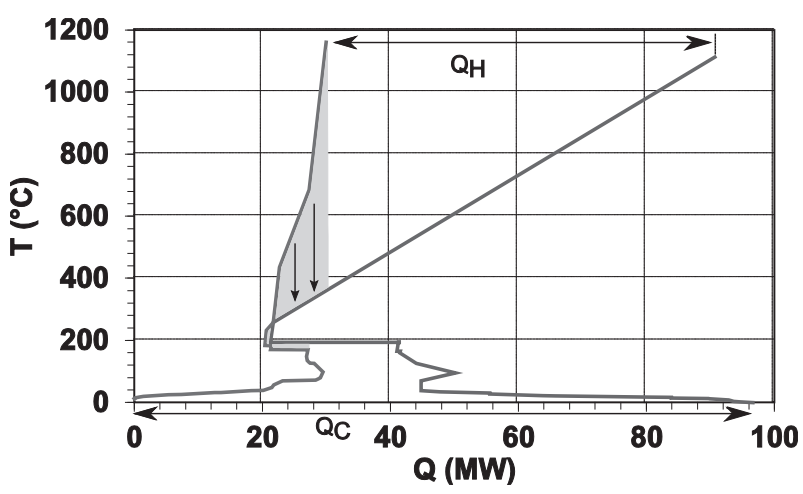

Fig. 7. Heat integration possibilities between the coke plant and the rest of the process.

by these.

\subsection{Joint Pinch Analysis of Blast Furnace and Steel Plant}

Finally an analysis was made of the whole plant to evaluate how the two parts (coke plant and blast furnace + steel plant) can exchange heat. To do that, the coke plant GCC (shown to the left in Fig. 6 and the blast furnace and steel plant (to the right in the same figure) are put in the same diagram. To make the two curves fit together, the coke plant GCC is laterally transposed and then placed as close to the blast furnace/steel plant GCC as the $\Delta \mathrm{T}_{\min }$ allows $\left(10^{\circ} \mathrm{C}\right)$.

The resulting GCC, including the stream data described above, is shown in Fig. 7. The cooling loads are simply added and the RH steam demand is the, barely visible, plateau at $200^{\circ} \mathrm{C}$ (the right tip of the pocket). Using the averaged heat from the BOF gas in the analysis would give the wrong idea about what is possible in the process, as it appears as a continuous source. Instead, the generated heat at 15 bar will represent that source, as it can be accumulated and delivered at an even pace.

Combining the two sites does not seem to be a feasible option just by investigating integration possibilities. It would, however, add a degree of flexibility to have a common steam system.

\section{Discussion}

\subsection{Effect of Non-continuous Flows}

One problem is that batch-wise processes in the steel plant cause fluctuations both in production and use of steam. These are partly but not totally stabilized by the accumulation in the steam domes and accumulators. The numerical values that have been evaluated in this study are calculated as the mean of the instantaneous production and consumtion. This is correct if and only if the buffer capacity is sufficient to compensate for all fluctuations in these streams. In reality this is not always the case, and mismatches occur in both directions. This sometimes causies purchase of steam, sometimes condensation. At $100 \%$ synchronization the steam from BOF should be enough to cover the need of steam, but in reality extra steam is often imported from the CHP plant to compensate for temporary lack.

The mismatch itself is a production problem and the economic effect is a yearly import of steam corresponding to an average value of around $3 \mathrm{MW}$. The remaining mismatch 
can be expected to increase the effect of the common steam system that was suggested in paragraph 3.3. In the modeling the mismatch will cause a discrepancy between calculated and real balance. This value is an indicator showing the degree of dynamic imperfection in the system, i.e., it should be treated as a result rather than as an error.

\subsection{Effect of Non-thermal Energy Conversions and Flows. Example: Modeling of the Blast Heating}

A large part of the energy reactions and streams in the steel plant involve non-thermal energy, e.g., chemical energy, mechanical energy, electricity etc. The pinch analysis treats the interaction between stream temperatures and the corresponding exchange of heat energy. This limits the use of Pinch analysis to the areas where these energies are dominating. It is, however, possible to gain information even if not all streams and processes are thermal. One example in this study is the results regarding heating of the blast for the blast furnace. The blast air is heated in the hot stove, which is a regenerative heat exchanger. The air is first compressed to roughly 2.5 bar, and the temperature increases to around $150^{\circ} \mathrm{C}$. After that it is heated to around $1100^{\circ} \mathrm{C}$ by contact with hot silica bricks. The bricks have been preheated by burning a mixture of blast furnace gas and coke oven gas and cold air in a ceramic burner. The relation of coke oven gas to blast furnace gas is adjusted to get the flame temperature that is necessary for the preheating (around $1250^{\circ} \mathrm{C}$ ). The non-thermal processes can cause blind spots in the pinch analysis of that unit

- The heating of the gas in the compressor is a conversion of mechanical energy and not visible.

- The burning of gas and air in the hot stove burner is a chemical reaction and not visible.

- The input of cold air to the blowing machine and the gas and air to the burners do not change temperature and are thus not hot or cold streams.

The GCC showing current load of the blast furnace - steel plant system (Fig. 5) shows a pocket with possible heat exchange from BOF steam to cold blast, i.e., the pinch analysis suggests that steam should be used to heat blast air. However, this was not considered to be fully feasible. With knowledge of the internal flows of the system the result could instead be interpreted as a general indication to supply available heat to that part of the system. In that case the recommendation would be to use the heat to preheat the air and perhaps also the gas to the hot stoves burner. As these gases are colder than the cold blast it would also be possible and more easy to use the heat in hot stove flue gas and the recommendation would be to begin with that. Thus the pinch analysis method is still appropriate, and the main conclusion is that it is necessary to conduct the interpretation of the results of the pinch study together with plant staff.

\subsection{Choice of System Boundary}

The main issue for an ore-based slabs producer is that the primary energy source (coal) also works as the reducing agent in the blast furnace. Thus, the energy input cannot be reduced by energy efficiency measures. Instead, any energy savings that are made will result in a larger energy surplus in the system. The released surplus energy is usually in the form of low or moderate temperature flows and it is crucial to find users for those streams, e.g., by pinch targeting.

The present study was made for units within the plant site. It is also of interest to widen the system boundary in order to find other possible users of excess heat, e.g. by including the city district heating network or other nearby industrial process plants.

\subsection{Possible Improvements}

The pinch targeting study of the coke plant showed that the steam boiler could be shut down if all the excess heat stream were utilized, thus liberating some coke oven gas. This can partly be done by utilizing the heat in the coke oven gas at high temperature, where risk of tar condensation is low. A thorough investigation of the tars that are present, and their respective condensation temperatures, must be done before such modifications are carried out.

The analysis shows a large energetic gain by transportation of flue gases and steam between the sites. However, under present conditions this can be judged as less realistic due to the distances involved. Combining the two sites does not seem to be a feasible option on the basis of heat integration possibilities. It would, however, add a degree of flexibility to have a common steam system.

\subsection{Usefulness for Steel Industry}

Based on the two pinch targeting studies presented, pinch analysis is recommended to be used in complex processes with extensive exchange of thermal energy, such as the coke oven gas cleaning area, while blast furnace and steel plant are less suitable. As heat is needed at high temperatures in the blast furnace and cooling is necessarily done with cold water, integration possibilities are scarce. Optimization of operating conditions is a more important efficiency measure in such cases.

As conditions can be different for different plant areas and problems a toolbox of diverse methods is probably preferable, i.e., pinch analysis should be used together with the other tools, not instead of them.

\section{Conclusions}

This paper presented the results of a pinch targeting study that was carried out for the steel plant site in Luleå.

This study identified possible savings of $9 \mathrm{MW}$ for the coke plant site facility.

Connection between the energy systems in the coke plant and the streams in the iron making/steelmaking areas of the site would enable further energy efficiency gains, but they were not considered to be feasible due to the distances involved. However, a common steam system could add a degree of flexibility.

Previous process integration studies had been conducted using mathematical programming and Exergy. Compared with these, pinch analysis is most useful where the energy system is dominated by creation, transport and exchange of thermal energy, e.g., the gas cleaning facility at the coke plant site.

A combined use of pinch analysis and other process integration methods is probably preferable, as conditions are different in different areas. 


\section{Acknowledgments}

The authors of this paper would like to thank Ida Engström and Rickard Broström at the steel plant in Luleå, for support with details and data, and Chuan Wang, MEFOS, for valuable comments. We also would like to thank the Swedish Energy Agency for financing the study.

\section{REFERENCES}

1) B. Linnhoff, D. W. Townsend, D. Boland and G. F. Hewitt: A User Guide on Process Integration for the Efficient Use of Energy, Rev. ed. by IChemE., Rugby, UK, (1994).

2) T. Gundersen: International Energy Agency Report, SINTEF Energy Research, Trondheim, Norway, (2000).

3) J. Klemes, F. Friedler and I. Bulatov: Sustainability in the Process Industry, McGraw-Hill, New York, USA, (2010).

4) Pinch Analysis for the Efficient Use of Energy, Water \& Hydrogen: http://canmetenergy.nrcan.gc.ca/sites/canmetenergy.nrcan.gc.ca/files/ pdf/fichier.php/codectec/En/2009-052/2009-052_PM-FAC_404DEPLOI_e.pdf

5) G. Wall: Energy, 13 (1988), 197.
6) C. Mapelli and S. Baragiola: Ironmaking Steelmaking, 33 (2006), 379.

7) M. Modesto and S Nebra: Energy, 31 (2006), 3261.

8) G. Wall: The 4th Int. Symp. on Second Law Analysis of Thermal Systems, ASME, New York, (1987), 131.

9) K. Nilsson and M. Söderström: Energy, 17 (1992), 945.

10) M. Larsson, P. Sandberg, J. Dahl, M. Söderström and H. Vuorinen: Int. J. Energy Res., 28 (2004), 1051.

11) C. Wang, M. Larsson, C. Ryman, C.-E. Grip, J.-O. Wikström, A. Johnsson and J. Engdahl: Int. J. Energy Res., 32 (2008), 1092.

12) C. Ryman and M. Larsson: ISIJ Int., 46 (2006), 1752.

13) M. Larsson and J. Dahl: ISIJ Int., 43 (2003), 1664

14) M. Larsson, C. Wang, J. Dahl, A. Wedholm, C. Samuelsson, M. Magnusson, H. O. Lampinen, F. Su and C.-E. Grip: Int. J. Green Energy, 3 (2006), 127.

15) C. Ryman: Iron Steel Technol., 8 ( 2011), 61.

16) P. Å. Frank: Personal communication.

17) C. E. Grip, M. Larsson and J. Dahl: Proc. 84th Steelmaking Conf., ISS, Warrendale, PA, (2001), 543.

18) K. Matsuda, T. Tanaka and M. E. Shigeki: http://www.aidic.it/pres11/ webpapers/29Matsuda.pdf

19) R. W. R. Zwart, A. Van der Drift, A. Bos, H. J. M. Visser, M. K. Cieplik and H. W. J. Könemann: Environ. Prog. Sustain. Energy, 28 (2009), 324. 